\title{
Estudo comparativo dos efeitos do extrato de Ginkgo biloba L. e Panax ginseng C.A. Meyer na reprodução de ratos machos e fêmeas Wistar
}

\author{
KUNTZE, L.B.; KONDO, A.K.; BEZERRA, B.T.S.; PINTO, T.; CAMARGO, I.C.C.* \\ Faculdade de Ciências e Letras, Departamento de Ciências Biológicas, Universidade Estadual Paulista - UNESP, \\ CEP: 19816-900, Assis-Brasil *camargo@assis.unesp.br
}

\begin{abstract}
RESUMO: Ginkgo biloba e Panax ginseng são plantas utilizadas na medicina tradicional. 0 objetivo do estudo foi avaliar a histologia gonadal de ratos machos e fêmeas Wistar submetidos aos tratamentos com o extrato de G. biloba $\left(120 \mathrm{mg} \mathrm{kg}^{-1}\right)$ ou $P$. ginseng $\left(200 \mathrm{mg} \mathrm{kg}^{-1}\right)$, e avaliar os parâmetros reprodutivos e fetais das ratas tratadas com as plantas. O grupo controle recebeu solução fisiológica $0,9 \%$. Os tratamentos foram efetuados por via oral através de gavage, duas vezes ao dia, durante quinze dias consecutivos. Após este período, machos $(n=18)$ e fêmeas $(n=18)$ foram sacrificados e as gônadas coletadas, pesadas e processadas para avaliação microscópica. Outras fêmeas $(n=18)$ foram acasaladas com machos não tratados para avaliação da fertilidade e produtos da gestação. Os resultados indicaram que o peso dos órgãos reprodutivos masculino e feminino não foi afetado pelos tratamentos. A estrutura gonadal dos machos e fêmeas mostrou o mesmo padrão histológico nos três grupos experimentais. O tratamento materno prégestacional com os extratos não promoveu alterações no desempenho reprodutivo das matrizes e nos parâmetros fetais. Concluiu-se que o extrato de $P$. ginseng ou $G$. biloba não causou toxicidade reprodutiva em ratos machos e fêmeas.
\end{abstract}

Palavras-chave: Ginkgo biloba, Panax ginseng, ovários, testículos, reprodução

ABSTRACT: Comparative study of effects of Ginkgo biloba L. and Panax ginseng C.A. Meyer extract on the reproduction of Wistar male and female rats. Ginkgo biloba and Panax ginseng are plants used in the traditional medicine. The aim of study was to analyse the gonadal histology of the Wistar male and female rats submitted to the treatments with extract of G. biloba $\left(120 \mathrm{mg} \mathrm{kg}^{-1}\right)$ or $P$. ginseng $\left(200 \mathrm{mg} \mathrm{kg}^{-1}\right)$, and to evaluate the reproductive and fetal parameters of female rats treated with the plants. The control group received physiological solution $0.9 \%$. The treatments were administered by oral gavage, twice/day, during fifteen consecutive days. After this period, male $(n=18)$ and female rats $(n=18)$ were sacrificed and the gonads collected, weighed and processed for microscopic evaluation. Another females $(n=18)$ were matted with not treated males for evaluation of fertility and pregnancy outcome. The results indicated that the male and feminine reproductive organs weight was not affected by treatments. The gonadal structure of male and female rats showed same histologic pattern in the three experimental groups. The pre-gestational treatment with the extracts not promoted alterations in the reproductive performance of dams and in the fetal parameters. It was concluded that the extract of $P$. ginseng or G. biloba not presented reproductive toxicity in the male and female rats.

Key words: Ginkgo biloba, Panax ginseng, ovaries, testes, reproduction

\section{INTRODUÇÃO}

A utilização de plantas com fins terapêuticos é das mais antigas formas de prática medicinal da humanidade. O medicamento fitoterápico difere da planta medicinal devido à elaboração da planta para determinada formulação específica, com conhecimento da eficácia e dos riscos do uso. Entre 250-500 mil espécies de plantas, somente cerca de
$5 \%$ têm sido estudadas fitoquimicamente e pequena porcentagem é avaliada sob os aspectos biológicos (Cechinel Filho \& Yunes, 1998).

$\mathrm{Na}$ busca do poder terapêutico das plantas na medicina popular, muitos usuários desconhecem que estas possam conter constituintes que promovem riscos toxicológicos. Há na literatura científica, vários

Recebido para publicação em 06/12/2009

Aceito para publicação em 28/11/2011

Rev. Bras. PI. Med., Botucatu, v.14, n.1, p.34-42, 2012. 
estudos a respeito dos efeitos farmacológicos dos diferentes constituintes de plantas medicinais. No entanto, pouco é conhecido sobre a toxicidade reprodutiva das plantas medicinais (Badami et al., 2003; Castro et al., 2005; Al-Yahya et al., 2006), tais como Panax ginseng e Ginkgo biloba.

Panax ginseng C. A. Meyer (Araliaceae) tem as raízes empregadas na medicina tradicional chinesa por ter importantes qualidades terapêuticas, em especial aquelas denominadas adaptogênicas, caracterizadas pela ação antiinflamatória e antioxidante. Frequentemente o $P$. ginseng é utilizado para aumentar o desempenho físico e melhorar a vitalidade, função imunológica, função sexual e fertilidade (Tesch, 2002). Contudo, não há estudos conclusivos sobre esta ação benéfica do $P$. ginseng. Há relatos científicos que sugerem haver redução no risco de certos tipos de câncer em pessoas que utilizam regularmente o $P$. ginseng.

Os principais componentes ativos do $P$. ginseng são no mínimo 18 ginsenosídeos, um grupo diverso de saponinas esteroidais, que podem atuar em diversos tecidos e produzir uma variedade de respostas farmacológicas complexas (Tesch, 2002). Outros componentes do P. ginseng incluem polissacarídeos, flavonóides, aminoácidos e vitaminas (Nocerino et al., 2000; Schenkel, 2007).

Estudos comprovaram a eficácia do $P$. ginseng como tratamento alternativo à disfunção erétil, pois os ginsenosídeos se mostraram capazes de intensificar a liberação de óxido nítrico pelas células endoteliais ou neurais, levando ao relaxamento dos corpos cavernosos (Nocerino et al., 2000; Murphy \& Lee, 2002; Andrade et al., 2007).

No aspecto reprodutivo, o extrato de $P$. ginseng administrado experimentalmente em ratos machos estimulou a formação dos gametas (Park et al., 2007) e os ginsenosídeos Rb2, Rc e Re, in vitro, demonstraram ação estimulatória sobre a motilidade e capacitação dos espermatozóides (Chen et al., 2001; Zhang et al., 2007). Em ratas submetidas ao protocolo de superovulação (Yu et al., 2003), as saponinas esteroidais do Korean ginseng foram responsáveis pelo aumento da qualidade dos oócitos.

Ginkgo biloba L. (Ginkgoaceae) é árvore de origem oriental, cujos extratos das folhas são amplamente utilizados na fitoterapia. O extrato padrão, conhecido como EGb 761, contém alguns traços de constituintes potencialmente perigosos, os ácidos ginkgólicos, mas garante uma certa quantidade de outros componentes ativos (por exemplo, 23-25\% de glicosídeos flavonóides e $6 \%$ de terpenos) (Hecker et al., 2002). Os componentes flavonóides atuam como antioxidantes e reduzem a fragilidade do capilar sanguíneo (Tesch, 2002), e os ginkgolídeos antagonizam o fator de ativação plaquetária (PAF), a qual induz a agregação plaquetária, degranulação dos neutrófilos e produção de radicais livres (Chung et al., 1987).

Extratos de G. biloba têm atividade estrogênica (Oh \& Chung, 2004) e podem ser úteis como uma alternativa à terapia de reposição hormonal em mulheres climatéricas e pós-menopáusicas, com efeitos quimiopreventivos sobre o câncer de mama (Oh \& Chung, 2006).

Em ratos machos, a administração oral de EGb 761 intensificou o comportamento copulatório, com indicação de efeito afrodisíaco do G. biloba (Yeh et al., 2008). Em células de Leydig cultivadas in vitro, os autores verificaram que o extrato padrão induziu a produção de testosterona.

Embora a administração de G. biloba em ratas Wistar, não determine alterações nas variáveis relacionadas com toxicidade sistêmica e reprodutiva (Castro et al., 2005), ginkgolídeos, in vitro, induziram a apoptose na massa celular interna, reduzindo a viabilidade dos blastocistos (Chan, 2005). Em ratas Wistar, a administração do extrato nas doses de 7 e $14 \mathrm{mg} \mathrm{kg}^{-1} \mathrm{dia}^{-1}$, durante a fetogênese e organogênese, induziram ao atraso no crescimento fetal intra-uterino (Pinto et al., 2007).

$\mathrm{Na}$ literatura são escassos os estudos que enfatizam os efeitos dos extratos de plantas medicinais no aspecto morfológico do trato reprodutor masculino e feminino, sendo de maior ênfase os relatos fetotoxicológicos. Assim, o objetivo do presente estudo foi avaliar a estrutura histológica gonadal de ratos machos e fêmeas da linhagem Wistar, submetidos ao tratamento com o extrato de Ginkgo biloba ou Panax ginseng, e analisar o desempenho reprodutivo e parâmetros fetais de ratas submetidas aos tratamentos.

\section{MATERIAL E MÉTODO}

\section{Animais}

Foram utilizados ratos machos e fêmeas da linhagem Wistar, com peso médio de 288 e $200 \mathrm{~g}$, respectivamente, e idade de 12 semanas no início do experimento. Os animais foram alojados em ambiente padrão com temperatura média de $22^{\circ} \mathrm{C}$ e luminosidade de $12 \mathrm{~h}$ de ciclo claro/escuro, os quais receberam água e ração comercial ad libitum. Todos os procedimentos foram aprovados pelo Comitê de Ética em Pesquisa da Faculdade de Ciências e Letras de Assis - UNESP, sob Protocolo 007/2008 e Processo 750/2008.

\section{Fitoterápico e preparação do extrato}

Os extratos secos provenientes das folhas de $G$. biloba e de raízes dessecadas de $P$. ginseng, foram adquiridos por compra dos fornecedores Deg Importadora de Produtos Químicos Ltda. (São Paulo, 
SP, Brasil) Lote 20060520, e Galena Química e Farmacêutica Ltda. (Campinas, SP, Brasil) Lote SB07-H010001, respectivamente. Os extratos foram administrados diariamente por meio da dissolução dos extratos secos, na proporção de 432 $\mathrm{mg}$ de extrato seco de G. biloba ou de $720 \mathrm{mg}$ de extrato seco de $P$. ginseng para $36 \mathrm{~mL}$ de solução fisiológica $0,9 \%$ e armazenados sob refrigeração.

\section{Procedimento experimental}

Os animais (dezoito machos e trinta e seis fêmeas) foram casualmente distribuídos nos grupos controle, tratado com extrato de G. biloba e tratado com extrato de $P$. ginseng, nos quais receberam por administração oral (gavage), respectivamente, solução fisiológica $0,9 \%, 120 \mathrm{mg} \mathrm{kg}^{-1}$ e $200 \mathrm{mg}$ $\mathrm{kg}^{-1}$, em volume de extrato de $10 \mathrm{~mL} \mathrm{~kg}^{-1}$, fornecidos duas vezes ao dia, durante quinze dias consecutivos, no mesmo horário (11:00 e 17:00 h).

O ciclo estral das ratas foi monitorado diariamente (entre 7:00-8:00 h) através da citologia esfoliativa vaginal, e o material foi corado pelo método Shorr / hematoxilina. As fases do ciclo foram identificadas, conforme o critério descrito por Marcondes et al. (2002).

No primeiro estro após o término do tratamento, metade das fêmeas $(n=18)$ foi sacrificada para obtenção das gônadas destinadas à análise histológica. As fêmeas restantes $(n=18)$ foram submetidas ao acasalamento com machos não tratados para avaliação dos parâmetros fetais. A prenhez foi confirmada pela presença de espermatozóides no esfregaço vaginal, considerando-se como primeiro dia da gestação e a laparotomia ocorreu no 19o dia gestacional.

Os machos $(n=18)$ foram sacrificados ao término dos tratamentos experimentais e os órgãos reprodutivos foram coletados, pesados e as gônadas seguidas para processamento histológico.

\section{Rotina histológica}

Machos e fêmeas submetidos a cada um dos tratamentos foram pesados e anestesiados com ketamina/xilasina (2:1) na dosagem de $20 \mathrm{mg}$ $\mathrm{kg}^{-1}$ de cada anestésico. Nas fêmeas foram coletados os ovários e útero, e nos machos, os testículos, epidídimos, complexo prostático e vesículas seminais, os quais foram pesados em balança analítica. Em ambos os sexos foram coletados o fígado e a hipófise. As gônadas foram submetidas à rotina histológica usual, obtendo-se secções de $5 \mu \mathrm{m}$ de espessura, incluídas em Paraplast (Labware Oxford - USA) e coradas com Hematoxilina - Eosina (HE), Tricrômico de Mallory e Azul de Toluidina, conforme descrito por Tolosa et al. (2003), para análise em microscopia de luz.
Análise dos parâmetros reprodutivos e fetais

Foram calculados os índices de fertilidade (no de fêmeas com espermatozóides presentes no esfregaço / no de fêmeas acasaladas x 100) e de gestação ( $\mathrm{n}$ - de fêmeas com fetos viáveis / no de fêmeas com espermatozóides no esfregaço x 100), bem como as taxas de perda pré-implantação [ $(\mathrm{n}$ de corpos lúteos - $\mathrm{n}$ o de implantes / $\mathrm{n}$ - de corpos lúteos $) \times 100]$ e perda pós-implantação [( $\mathrm{n}$ o de implantes - no de fetos / no de implantes) x 100], conforme descrito por Weidner \& Sigwart (2001) e Damasceno et al. (2008). Registrou-se o número de implantes uterinos, número de corpos lúteos gravídicos, número de reabsorções embrionárias, número de fetos por ninhada, peso da ninhada e número e peso das placentas.

A avaliação da fetotoxicidade foi realizada através da morfologia externa fetal seguindo alguns critérios de Wilson, conforme Taylor (1986). Sob estereomicroscópio cada feto foi analisado quanto ao aspecto dos olhos e orelha, contorno do crânio, exame da face e focinho, extremidades (tamanho, posição e dígitos) e anormalidades no tronco e cauda. O sexo fetal foi determinado pela distância anogenital (Damasceno et al., 2008).

Sinais de toxicidade materna sistêmica como perda de peso, debilidade, piloereção e morte foram observadas periodicamente.

\section{Análise estatística}

Os registros biométricos de peso corpóreo e peso das estruturas orgânicas, assim como os registros dos parâmetros reprodutivos e fetais, foram analisados por meio da análise de variância não paramétrica de Kruskal-Wallis, complementada com o teste de Dunn. O nível de significância foi estabelecido para $p<0,05$.

\section{RESULTADO}

Avaliação dos efeitos do G. biloba ou $P$. ginseng no peso corpóreo e peso absoluto e relativo das estruturas orgânicas de fêmeas e machos

Os resultados indicaram que o peso corpóreo e o peso absoluto e relativo das estruturas orgânicas das fêmeas e machos submetidos aos tratamentos com $G$. biloba ou $P$. ginseng não foram afetados significativamente $(p>0,05)$, em comparação ao grupo controle (Tabelas 1 e 2 ).

\section{Avaliação dos efeitos do G. biloba ou $P$. ginseng na estrutura histológica gonadal de fêmeas e machos}

Nos três grupos experimentais (Figuras 1 A, C, E), a estrutura histológica ovariana foi similar, contendo região cortical e medular distintas, com unidades foliculares em diversos estágios de 
TABELA 1. Peso corpóreo e peso absoluto e relativo do fígado, hipófise e órgãos reprodutivos das fêmeas dos grupos controle, tratado com G. biloba (120 mg kg-1, gavage) e tratado com $P$. ginseng (200 $\mathrm{mg} \mathrm{kg}^{-1}$, gavage).

\begin{tabular}{cccc}
\hline Parâmetros de pesos & GruposControle & experimentaisG. biloba & P. ginseng \\
\hline Corpóreo $(\mathrm{g})$ & $263,5 \pm 31,3$ & $274,0 \pm 51,3$ & $268,5 \pm 27,3$ \\
Hepático $(\mathrm{g})$ Hepático $(\mathrm{g} \%)$ & $9,1 \pm 1,83,6 \pm 0,8$ & $10,3 \pm 1,43,7 \pm 0,8$ & $9,9 \pm 0,73,7 \pm 0,3$ \\
Hipofisário (g)Hipofisário $(\mathrm{mg} \%)$ & $0,01 \pm 0,0034,0 \pm 0,9$ & $0,01 \pm 0,014,0 \pm 2,0$ & $0,01 \pm 0,0044,1 \pm 1,5$ \\
Uterino (g)Uterino (g\%) & $0,4 \pm 0,10,2 \pm 0,06$ & $0,5 \pm 0,20,2 \pm 0,09$ & $0,5 \pm 0,10,2 \pm 0,04$ \\
Ovariano (g)Ovariano (g\%) & $0,1 \pm 0,010,02 \pm 0,006$ & $0,1 \pm 0,040,03 \pm 0,01$ & $0,1 \pm 0,010,03 \pm 0,006$ \\
\hline
\end{tabular}

$\mathrm{N}=6 /$ grupo.Valores apresentados como mediana \pm desvio interquartílico. Kruskal-Wallis, teste de Dunn, $p>0,05$.

TABELA 2. Peso corpóreo e peso absoluto e relativo do fígado, hipófise e órgãos reprodutivos dos machos dos grupos controle, tratado com G. biloba (120 mg kg-1, gavage) e tratado com $P$. ginseng (200 $\mathrm{mg} \mathrm{kg}^{-1}$, gavage).

\begin{tabular}{cccc}
\hline Parâmetros de pesos & Grupos Controle & experimentaisG. biloba & P. ginseng \\
\hline Corpóreo $(\mathrm{g})$ & $369,0 \pm 29,8$ & $374,0 \pm 77,5$ & $429,5 \pm 89,0$ \\
Hepático $(\mathrm{g})$ & $12,8 \pm 2,3$ & $14,0 \pm 4,5$ & $15,4 \pm 4,7$ \\
Hepático $(\mathrm{g} \%)$ & $3,4 \pm 0,3$ & $3,7 \pm 0,6$ & $3,8 \pm 0,5$ \\
Hipofisário $(\mathrm{g})$ & $0,01 \pm 0,002$ & $0,01 \pm 0,003$ & $0,01 \pm 0,01$ \\
Hipofisário $(\mathrm{mg} \%)$ & $2,2 \pm 0,4$ & $2,0 \pm 1,0$ & $2,0 \pm 0,5$ \\
Testicular $(\mathrm{g})$ & $3,1 \pm 0,6$ & $3,2 \pm 0,5$ & $3,3 \pm 0,2$ \\
Testicular $(\mathrm{g} \%)$ & $0,8 \pm 0,1$ & $0,8 \pm 0,2$ & $0,9 \pm 0,1$ \\
Epididimário $(\mathrm{g})$ & $1,2 \pm 0,2$ & $1,2 \pm 0,2$ & $1,2 \pm 0,1$ \\
Epididimário $(\mathrm{g} \%)$ & $0,3 \pm 0,04$ & $0,3 \pm 0,06$ & $0,3 \pm 0,02$ \\
Prostático $(\mathrm{g})$ & $0,7 \pm 0,3$ & $0,6 \pm 0,3$ & $0,5 \pm 0,2$ \\
Prostático $(\mathrm{g} \%)$ & $0,2 \pm 0,06$ & $0,1 \pm 0,03$ & $0,1 \pm 0,05$ \\
Vesículas Seminais $(\mathrm{g})$ & $1,9 \pm 0,4$ & $1,8 \pm 0,6$ & $1,8 \pm 0,5$ \\
Vesículas seminais $(\mathrm{g} \%)$ & $0,5 \pm 0,08$ & $0,4 \pm 0,09$ & $0,5 \pm 0,14$ \\
\hline
\end{tabular}

$\mathrm{N}=6$ /grupo. Valores apresentados como mediana \pm desvio interquartílico. Kruskal-Wallis, teste de Dunn, $p>0,05$.

maturação e com presença de corpos lúteos bem desenvolvidos. As células luteínicas mostraram padrão morfológico normal nos grupos controle (Figura 1 B) e tratado com G. biloba (Figura 1 D), porém, nas ratas tratadas com $P$. ginseng (Figura $1 \mathrm{~F}$ ) algumas células exibiram característica degenerativa e atividade macrofágica.

Os testículos dos ratos dos grupos controle (Figura 2 A), e tratados com G. biloba (Figura 2 B) e $P$. ginseng (Figura $2 \mathrm{C}$ ) apresentaram túbulos seminíferos com citoarquitetura epitelial normal, constituídos por várias camadas de células germinativas. O interstício tubular apresentou constituição de tecido conjuntivo frouxo, ricamente vascularizado, contendo células intersticiais de Leydig próximas aos vasos sanguíneos (Figura $2 \mathrm{~A}$ ).

\begin{abstract}
Avaliação dos efeitos do G. biloba ou $P$. ginseng nos parâmetros reprodutivos e fetais de ratas submetidas aos tratamentos no período prégestacional

O tratamento materno com o extrato de $G$. biloba ou $P$. ginseng não promoveu alteração significativa $(p>0,05)$ nos parâmetros reprodutivos e fetais, em comparação ao grupo controle (Tabela 3). As taxas de fertilidade e gestação foram similares nos três grupos experimentais, e a análise da morfologia externa fetal não demonstrou alterações na estrutura corporal nos grupos tratados com as plantas medicinais.
\end{abstract}

\section{DISCUSSÃO}

Os constituintes tóxicos do G. biloba e $P$. 

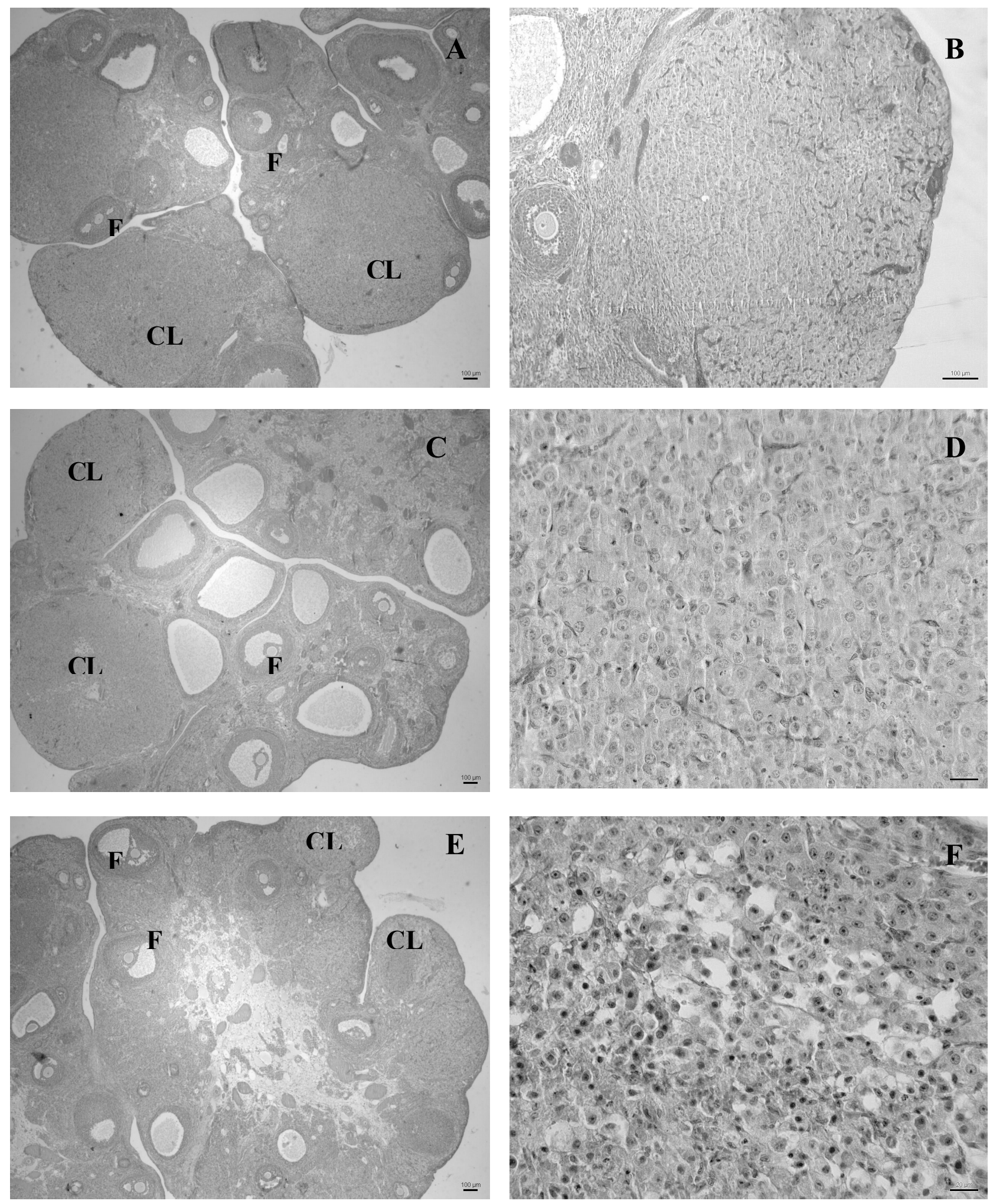

FIGURA 1. Secção histológica de ovário de ratas dos grupos controle (A, B) e tratados com G. biloba (120 mg kg-1, gavage) (C, D) e $P$. ginseng (200 $\mathrm{mg} \mathrm{kg}^{-1}$, gavage) (E, F). Observar a presença de corpos lúteos (CL) e unidades

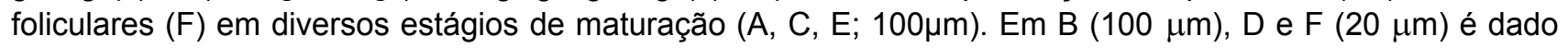
destaque às células luteínicas. 

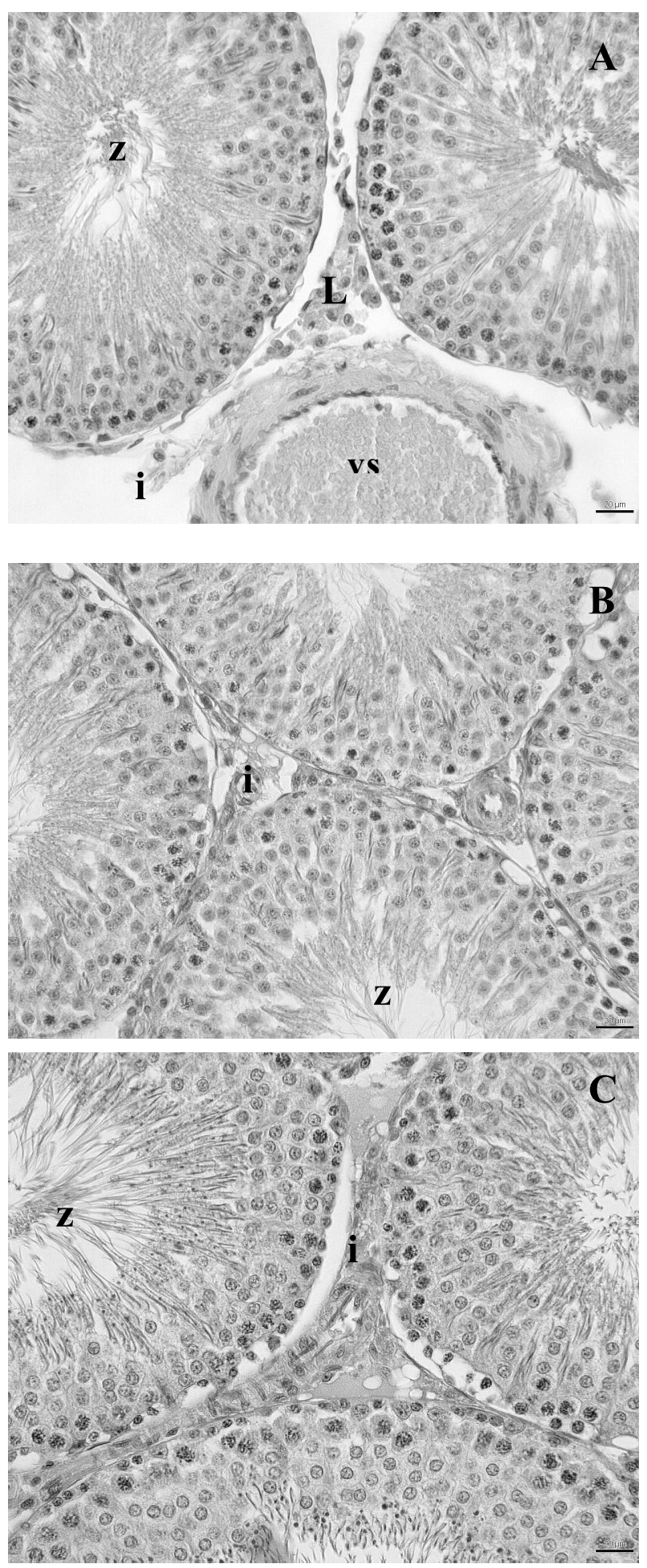

FIGURA 2. Secção histológica de testículos de ratos dos grupos controle (A) e tratados com G. biloba (120 mg kg-1 , gavage) (B) e P.ginseng (200 mg kg-1, gavage) (C). Nos três grupos, os túbulos seminíferos apresentaram epitélio com várias camadas de células germinativas e espermatozóides ( $z$ ) na luz. No interstício tubular (i) são observadas as células de Leydig (L). vs $=$ vaso sanguíneo. Barras $=20 \mu \mathrm{m}$. ginseng não foram capazes de alterar o peso corpóreo e o peso absoluto e relativo das estruturas orgânicas dos ratos machos e fêmeas. Estes animais apresentaram aspecto saudável durante o período em que receberam os extratos de G. biloba $\left(120 \mathrm{mg} \mathrm{kg}^{-1}\right)$ e $P$. ginseng $\left(200 \mathrm{mg} \mathrm{kg}^{-1}\right)$, indicando que estes fitoterápicos nas doses utilizadas e no curto período de duração do tratamento, foram seguros aos animais. Castro et al. (2005) trataram ratos machos e fêmeas Wistar com extrato seco liofilizado de G. biloba na dose de $17 \mathrm{mg} \mathrm{kg}^{-1}$, durante longo período (91 dias em machos e 77 dias em fêmeas). Verificaram que a massa corpórea e a massa relativa do fígado, rins, baço e coração não foram afetadas pelo $B$. biloba em ambos os sexos. No mesmo estudo, a avaliação dos pesos relativos dos testículos, epidídimos, próstata e vesículas seminais nos ratos, e dos pesos relativos dos ovários e útero nas fêmeas, demonstrou que o extrato de $G$. biloba não promoveu toxicidade sistêmica nos órgãos reprodutivos. Al-Yahya et al. (2006) administraram em camundongos o extrato aquoso de G. biloba nas doses de 25,50 ou $100 \mathrm{mg}$ $\mathrm{kg}^{-1}$ durante 90 dias, e verificaram que o peso médio da cauda do epidídimo aumentou na dose de 50 e $100 \mathrm{mg} \mathrm{kg}^{-1}$, e o peso da próstata aumentou na dose de $100 \mathrm{mg} \mathrm{kg}^{-1}$. Os pesos relativos dos testículos e vesículas seminais não foram afetados pelo tratamento. Similarmente, a administração de $50 \mathrm{mg}$ $\mathrm{kg}^{-1}$ de G. biloba em ratos (Yeh et al., 2008), não influenciou o peso testicular. Os resultados do presente estudo demonstraram inexistência de efeito tóxico promovido pelo G. biloba sobre os pesos dos órgãos reprodutivos, fígado e hipófise dos machos e fêmeas, confirmando os relatos de outros estudos, que empregaram diferentes doses e períodos de tratamentos.

A administração de Panax ginseng às fêmeas deste estudo, e Korean ginseng no estudo realizado por Yu et al. (2003), demonstrou que os fitoterápicos não afetaram o peso das gônadas.

O ovário pode ser considerado um agregado de três tecidos endócrinos, o estroma, o folículo e o corpo lúteo. Os pesos destes tecidos constituem o peso líquido da gônada (Shivalingappa et al., 2002). No presente estudo, as ratas tratadas com G. biloba ou $P$. ginseng mantiveram o peso absoluto e relativo, e a estrutura do tecido ovariano similares ao grupo controle. A foliculogênese e a luteogênese não foram influenciadas pelas plantas medicinais, nas doses e período de tratamento utilizados. Castro et al. (2005) não observaram alterações morfológicas gonadais em ratas tratadas com G. biloba durante os períodos de pré-acasalamento, acasalamento, gestação e lactação. Yu et al. (2003) verificaram que o tratamento com saponinas do Korean ginseng reduziu a atresia folicular nos ovários de ratas imaturas superovuladas com gonadotrofina sérica de égua prenhe (PMSG). 
TABELA 3. Parâmetros reprodutivos e fetais nos grupos controle, tratado com G. biloba (120 $\mathrm{mg} \mathrm{kg}^{-1}$, gavage) e tratado com $P$. ginseng $\left(200 \mathrm{mg} \mathrm{kg}^{-1}\right.$, gavage).

\begin{tabular}{cccc}
\hline Parâmetros & GruposControle & experimentais G. biloba & P. ginseng \\
\hline № de fêmeas & 6 & 6 & 6 \\
Taxa de fertilidade (\%) & 100 & 100 & 100 \\
Taxa de gestação (\%) & 100 & 100 & 100 \\
Peso do útero gravídico (g) & $44,1 \pm 9,1$ & $42,2 \pm 11,8$ & $37,9 \pm 7,8$ \\
№ de fetos na ninhada & $13,0 \pm 3,2$ & $12,0 \pm 4,2$ & $11,5 \pm 3,2$ \\
Peso da ninhada (g) & $21,7 \pm 4,7$ & $19,7 \pm 7,4$ & $19,0 \pm 4,7$ \\
№ de placentas & $13,0 \pm 3,2$ & $12,0 \pm 4,2$ & $11,5 \pm 3,2$ \\
Peso das placentas (g) & $5,7 \pm 1,8$ & $5,0 \pm 1,5$ & $4,7 \pm 1,2$ \\
№ de implantes & $13,0 \pm 2,0$ & $12,0 \pm 4,5$ & $12,0 \pm 4,2$ \\
Perda pré-implantação (\%) & $0-3,3$ & $0-9,9$ & $0-15,7$ \\
Perda pós-implantação (\%) & $0-8,8$ & $0-1,5$ & $0-5,3$ \\
№ de fetos machos & $6,0 \pm 3,5$ & $5,0 \pm 2,5$ & $4,5 \pm 3,0$ \\
№ de fetos fêmeas & $6,0 \pm 1,7$ & $6,0 \pm 2,5$ & $6,0 \pm 1,2$ \\
\hline
\end{tabular}

$\mathrm{N}=6$ /grupo. Valores apresentados como mediana \pm desvio interquartílico. Kruskal-Wallis, teste de Dunn, $p>0,05$.

No aspecto reprodutivo masculino, é descrito que substâncias tóxicas ou produtos de sua biotransformação no organismo podem atravessar a barreira testicular, atuar sobre os tipos celulares existentes na gônada e, interferir na espermatogênese e/ou esteroidogênese (Castro et al., 2005). No presente estudo, os constituintes do G. biloba e $P$. ginseng não promoveram toxicidade testicular, quando avaliada pela análise da estrutura citohistológica dos túbulos seminíferos e interstício tubular. Os compartimentos tubular e intersticial apresentaram aspecto semelhante aos verificados nos animais do grupo controle. Vários túbulos seminíferos apresentaram gametas na luz, ou presos ao epitélio germinativo, indicando a ocorrência da espermatogênese.

Há vários estudos na literatura que relataram sobre o efeito protetor do G. biloba e $P$. ginseng sobre os testículos. Akgül et al. (2008) provocaram danos testiculares em ratos e observaram que o aspecto histológico das gônadas no grupo que recebeu o extrato de G. biloba manteve-se normal. Kumar et al. (2003) verificaram que o extrato de ginseng forneceu eficaz proteção aos testículos de camundongos contra a radiação gama. $O$ tratamento com o extrato de $P$. ginseng $\left(20 \mathrm{mg} \mathrm{kg}^{-1}\right)$ durante sete dias consecutivos, reduziu a degeneração de células espermatogênicas e células de Sertoli em testículos de ratos, provocada pela administração de EDTA, provavelmente devido à ação do ginsenosídeo $\mathrm{Rg} 3$ e o papel antioxidante (Khalil et al., 2008).

$\mathrm{Na}$ avaliação do desempenho reprodutivo das ratas tratadas com os extratos de G. biloba e $P$. ginseng durante o período pré-gestacional (15 dias), verificou-se neste estudo que houve ausência de efeito negativo das doses utilizadas de cada extrato sobre as taxas de fertilidade e gestação. No entanto, AlYahya et al. (2006) relataram que houve redução na fertilidade de camundongos fêmeas submetidas ao tratamento pré-gestacional (90 dias), com alta dose de G. biloba $\left(100 \mathrm{mg} \mathrm{kg}^{-1}\right)$. Estudo in vitro (Ondrizek et al., 1999) demonstrou que alta dose do extrato de G. biloba $\left(1 \mathrm{mg} \mathrm{mL}^{-1}\right)$, inibiu a fertilização de hamsters devido à degeneração oocitária e redução da viabilidade espermática.

Nos bioensaios de avaliação de toxicidade fetal são considerados os fatores de mortalidade, presença de anomalias e redução no peso corpóreo. A toxicidade materna inclui sinais clínicos, alteração no comportamento e ganho reduzido de peso durante a gestação (Chernoff et al., 2008). Os efeitos reprodutivos promovidos pelo G. biloba podem ser atribuídos à ação de um ou mais constituintes tóxicos da planta (Al-Yahya et al., 2006). Os ácidos ginkgólicos, presentes em extratos de G. biloba apresentam potencial citotóxico (Hecker et al., 2002) e são genotóxicos e carcinogênicos (Gutendorf et al., 2001). Neste estudo, nenhuma evidência de toxicidade materna e fetal foi observada quando as ratas receberam o extrato de G. biloba $\left(120 \mathrm{mg} \mathrm{kg}^{-1}\right)$ no período pré-gestacional. No entanto, Al-Yahya et al. (2006) verificaram que alta dose de G. biloba $(100 \mathrm{mg}$ $\mathrm{kg}^{-1}$ ), administrada durante 90 dias antes da concepção, causou perdas embrionárias préimplantacional. A administração de G. biloba (7 e 14 
$\left.\mathrm{mg} \mathrm{kg}^{-1} \mathrm{dia}^{-1}\right)$ durante a fetogênese e organogênese (8o ao 20 dia gestacional), reduziu o peso fetal, não havendo sinais de toxicidade materna (Pinto et al., 2007). Estudo realizado por Fernandes et al. (2010) revelou que a administração de diferentes doses de G. biloba $\left(3,5 ; 7,0\right.$ e 14,0 $\left.\mathrm{mg} \mathrm{kg}^{-1}\right)$ em ratas, durante o período de trânsito tubário até a implantação (1ao 8o dia gestacional), não afetou as variáveis maternas e fetais analisadas. Os autores concluíram que apesar do fato de ser relatado que os constituintes isolados do G. biloba promovem vários efeitos nocivos, as doses empregadas não causaram toxicidade materna, morte embrionária, retardo no crescimento e/ou malformações fetais.

Chan et al. (2003) realizaram estudo in vitro sobre a ação do ginsenosídeo Rb1 $\left(50 \mu \mathrm{g} \mathrm{mL}^{-1}\right)$, presente no meio de cultura com embriões de ratos de nove dias e verificaram que houve redução no número de somitos e comprimento cefalo-caudal. Esta avaliação demonstrou ação indutora teratogênica direta do ginsenosídeo Rb1 aos embriões. No presente estudo, o extrato de $P$. ginseng não demonstrou evidências de atividade teratogênica visto que todas as ratas geraram progênies normais.

A discrepância nos resultados obtidos em vários estudos toxicológicos se deve principalmente às diferenças nas doses empregadas, período de tratamento (pré-gestacional ou gestacional), fase da gestação submetida aos efeitos dos fitoterápicos, duração do tratamento e tipo de ensaio (in vitro ou in vivo). Desta forma, estas variáveis devem ser consideradas na avaliação dos efeitos tóxicos promovidos pelos fitoterápicos em estudo.

Os efeitos do $G$. biloba e $P$. ginseng são enfatizados principalmente em estudos mutagênicos, teratogênicos e carcinogênicos, sendo pouca atenção atribuída à morfologia do trato reprodutor. Assim, os resultados da presente pesquisa vêm contribuir para os estudos toxicológicos reprodutivos, indicando que nas condições experimentais empregadas, o G. biloba e o $P$. ginseng não promoveram toxicidade gonadal em machos e fêmeas, e não alteraram o desempenho reprodutivo das matrizes, bem como os parâmetros fetais.

\section{AGRADECIMENTO}

À Fundação de Amparo à Pesquisa do Estado de São Paulo - FAPESP, pelo auxílio financeiro (Proc. 08/53809-3).

\section{REFERÊNCIA}

AKGÜL, T. et al. Ginkgo biloba (EGb 761) usage attenuates testicular injury induced by testicular ischemia/ reperfusion in rats. International Journal of Urology and
Nephrology, v.40, n.3, p.685-90, 2008.

AL-YAHYA, A.A. et al. Studies on the reproductive, cytological and biochemical toxicity of Ginkgo biloba in Swiss albino mice. Journal of Ethnopharmacology, v.107, n.2, p.222-8, 2006.

ANDRADE, E. et al. Study of the efficacy of Korean Red Ginseng in the treatment of erectile dysfunction. Asian Journal of Andrology, v.9, n.2, p.241-4, 2007.

BADAMI, S. et al. Antifertility activity of Derris brevipes variety coriacea. Journal of Ethnopharmacology, v.84, n.1, p.99-104, 2003.

CASTRO, A.P.; MELLO, F.B.; MELLO, J.R.B. Avaliação toxicológica do Ginkgo biloba sobre a fertilidade e reprodução de ratos Wistar. Acta Scientiae Veterinariae, v.33, n.3, p.265-9, 2005.

CECHINEL FILHO, V.; YUNES, R.A. Estratégias para obtenção de compostos farmacologicamente ativos a partir de plantas medicinais. Conceitos sobre modificação estrutural para otimização da atividade. Química Nova, v.21, p.99-105, 1998.

CHAN, L.Y.; CHIU, P.Y.; LAU, T.K. An in-vitro study of ginsenoside $\mathrm{Rb} 1$-induced teratogenicity using a whole rat embryo culture model. Human Reproduction, v.18, n.10, p.2166-8, 2003.

CHAN, W.H. Ginkgolides induce apoptosis and decrease cell numbers in mouse blastocysts. Biochemical and Biophysical Research Communications, v.338, n.2, p.1263-7, 2005.

CHEN, J.C. et al. Effects of ginsenoside Rb2 and Rc on inferior human sperm motility in vitro. American Journal of Chinese Medicine, v.29, n.1, p.155-60, 2001.

CHERNOFF, N. et al. The relationship of maternal and fetal toxicity in developmental toxicology bioassays with notes on the biological significance of the "no observed adverse effect level”. Reproductive Toxicology, v.25, n.2, p.192-202, 2008.

CHUNG, K.F. et al. Effect of ginkgolide mixture in antagonizing skin and platelet responses to platelet activating factor in man. Lancet, v.329, n.31, p.248-51, 1987.

DAMASCENO, D.C. et al. Anomalias congênitas: estudos experimentais. Belo Horizonte: Coopmed Editora Médica, 2008. 102p.

FERNANDES, E.S. et al. Effects of Ginkgo biloba extract on the embryo-fetal development in Wistar rats. Birth Defects Research (Part B), v.89, n.2, p.133-8, 2010.

GUTENDORF, B.; REGAN, J.; WESTENDORF, J. Induction of DNA strand breaks and tumor promotion in primary rat hepatocytes by ginkgolic acids. Toxicologist, v.60, p.288, 2001.

HECKER, H. et al. In vitro evaluation of cytotoxic potential of alkylphenols from Ginkgo biloba L. Toxicology, v.177, n.2-3, p.167-77, 2002.

KHALIL, W. K. B. et al. The inhibitory effects of garlic and Panax ginseng extract standardized with ginsenoside Rg3 on the genotoxicity, biochemical, and histological changes induced by ethylenediaminetetraacetic acid in male rats. Archives of Toxicology, v.82, n.3, p.183-95, 2008.

KUMAR, M. et al. Radioprotective effect of Panax ginseng on the phosphatases and lipid peroxidation level in testes of Swiss albino mice. Biological Pharmaceutical Bulletin, v.38, n.3, p.308-12, 2003. 
MARCONDES, F.K.; BIANCHI, F.J.; TANNO, A.P. Determination of the estrous cycle phases of rats: some helpful considerations. Brazilian Journal of Biology, v.62, n.4A, p.609-14, 2002.

MURPHY, L.L.; LEE, T.J. Ginseng, sex behavior, and nitric oxide. Annals of the New York Academy of Sciences, v.962, p.372-7, 2002.

NOCERINO, E.; AMATO, M.; IZZO, A.A. The aphrodisiac and adaptogenic properties of ginseng. Fitoterapia, v.71, n.1, p.S1-S5, 2000.

$\mathrm{OH}$, S.M.; CHUNG, K.H. Estrogenic activities of Ginkgo biloba extracts. Life Sciences, v.74, n.11, p.1325-35, 2004. $\mathrm{OH}$, S.M.; CHUNG, K.H. Antiestrogenic activities of Ginkgo biloba extracts. Journal of Steroid Biochemistry \& Molecular Biology, v.100, n.4-5, p.167-76, 2006.

ONDRIZEK, R.R. et al. An alternative medicine study of herbal effects on the penetration of zona-free hamster oocytes and the integrity of sperm deoxyribonucleic acid. Fertility \& Sterility, v.71, n.3, p.517-22, 1999.

PARK, W.S. et al. Korean ginseng induces spermatogenesis in rats through the activation of cAMPresponsive element modulator (CREM). Fertility and Sterility, v.88, n.4, p.1000-2, 2007.

PINTO, R.M. et al. Intra-uterine growth retardation prenatal administration of Ginkgo biloba to rats. Reproductive Toxicology, v.23, n.4, p.480-5, 2007.

SCHENKEL, E.P. Saponinas. In: SIMÕES, C.M.O. (Ed.).
Farmacognosia: da planta ao medicamento. Porto Alegre/ Florianópolis: Ed. da UFRGS/UFSC, 2007. p.71140.

SHIVALINGAPPA, $\mathrm{H}$. et al. Effect of ethanol extract of Rivea hypocrateriformis on the estrous cycle of the rat. Journal of Ethnopharmacology, v.82, n.1, p.11-7, 2002.

TAYLOR, P. Practical Teratology. New York: Academic Press, 1986. 157p.

TESCH, B.J. Herbs commonly used by women: an evidence-based review. Disease-a-Month, v.48, n.10, p.671-96, 2002.

TOLOSA, E.M.C. et al. Manual de Técnicas para Histologia Normal e Patológica. 2.ed. Barueri: Manole, 2003. 331p.

YEH, K.Y. et al. Ginkgo biloba extract enhances male copulatory behavior and reduces serum prolactin levels in rats. Hormones and Behavior, v.53, n.1, p.225-31, 2008. $\mathrm{YU}$, W.J. et al. Modulating effects of Korean ginseng saponins on ovarian function in immature rats. Biological Pharmaceutical Bulletin, v.26, n.11, p.1574-80, 2003.

WEIDNER, M.S.; SIGWART, K. Investigation of the teratogenic potential of a Zingiber officinale extract in the rat. Reproductive Toxicology, v.15, n.1, p.75-80, 2001.

ZHANG, H. et al. Ginsenoside Re promotes human sperm capacitation through nitric oxide-dependent pathway. Molecular Reproduction and Development, v.74, n.4, p.497-501, 2007. 